\title{
Review of: "Land Use Cover changes in the western escarpment of Rift Valley in the Gamo Zone, Southern Ethiopia"
}

Shahid Rahmat

Potential competing interests: The author(s) declared that no potential competing interests exist.

\section{1)Line 52: -}

The rapid growth and expansion 51 of urban centers, population pressure, scarcity of land, changing technologies are among the 52 many drivers of LULC in the world today.

"changes" can be added after LULC for better clarity.

2) Line 64-69: -

Noted that close to $40 \%$ of Ethiopia might have been covered by high forests and that about $16 \%$ of the land area was covered by high forests in the early 1950s (EFAP 1994). In the early 1980s the high forest cover of Ethiopia declined to $3.6 \%$ and further declined to $2.7 \%$ in 1989.

Provide the recent estimate of forest cover if possible.

3) Line 103 (Table 1): -

'Projected population' is more appropriate instead of 'Projection population'.

4) Line 156-158: -

Supervised classification into four land classes were categories and distinguished into farmlands, forest lands, settlement, water bodies and wetlands (Table 3).

Mentions 'settlement' as one of the four classes of land use.

Line 222-223: -

also showed that urban settlements and farmland expansion gained the most in the area compared to other LULC types, while forest areas exhibited a decreasing trend.

Mentions 'urban settlements' as one of the land-use classes.

Maintain consistency.

5) Line 243 (Table 5): -

Rate of change of land-use has been slowed down in the period of 1999-2019.

Discuss the possible reasons.

6) Line 277-279: -

The threshold value of NDVI was approximately 0.73 (Figure 6). The pixels having an NDVI value above the threshold were identified as vegetated areas, while low NDVI values represented non-vegetated areas.

Line 281: - 
NDVI values in the range of 0.51 to 0.73 were considered as vegetation cover areas .

These two statements show inconsistency. Clarify, whether the range of NDVI for vegetation cover is 0.51 to 0.73 or it is above 0.73 .

7) Line 289: -

Explain the terms FGD and KIT

8) Line 292 (Table 10): -

Explain Frequency, \% and Rank. How it is determined?

9) Line 292 (Table 10): -

Agricultural expansion is Rank 1 in Proximate causes of LULC changes.

Line 293-294: -

The demographic data of the study area over the past three decades has revealed that population pressure ranked as the top cause of LULC changes.

Explain the reason behind this inconsistency. 